\title{
Editorial
}

\section{More Should Be Done to Protect Surgical Patients From Intraoperative Hepatitis B Infection}

\author{
Shirley Paton, RN, MN; Shimian Zou, MD, PhD; Antonio Giulivi, MD, FRCPC
}

When do we, as a society, have the right or the duty to deny a person's right to work in a chosen profession? The article by Spijkerman et al. ${ }^{1}$ in this issue of Infection Control and Hospital Epidemiology once again raises this question. The article reports that a surgeon was unresponsive to repeated attempts at hepatitis $B$ vaccination, and then was infected with hepatitis B at least a decade before discovery through public health department investigations of symptomatic infections among some of his most recent patients. During the course of 4 years, the surgeon, unknowingly infected with hepatitis $\mathrm{B}$ virus (HBV), appears to have transmitted HBV to 28 patients.

Since 1970 , more than 375 patients worldwide have been infected with hepatitis B from their surgeon. In the United States, 19 patients were infected from a cardiothoracic surgeon who tested positive for both hepatitis $B$ surface antigen (HBsAg) and hepatitis B e antigen ( $\mathrm{HBeAg}){ }^{2}$ In 1996, in the United Kingdom, 20 patients were infected from a cardiovascular surgeon who tested positive for HBeAg. ${ }^{3}$ In 1994, following hip replacement surgery, a Welsh woman was infected and died of acute hepatitis B that was shown to be genetically identical to her surgeon's hepatitis $\mathrm{B}$; the surgeon tested positive for $\mathrm{HBsAg}$ and antibody to hepatitis $\mathrm{B}$ e antigen (anti-HBe) and negative for HBeAg. ${ }^{4}$ In Canada, an orthopedic surgeon who tested positive for $\mathrm{HBeAg}$ infected 4 patients. ${ }^{5}$ Now, in this issue, we read that a surgeon from The Netherlands who tested positive for $\mathrm{HBsAg}$ and $\mathrm{HBeAg}$ infected 28 patients during 4 years. ${ }^{1}$ There was transmission to 28 patients during both high-risk and exposure-prone procedures, and also unexpectedly during low-risk procedures. Spijkerman et al. found that the surgeon's infection control practices were adequate; transmission occurred even when no break in infection control procedure or surgical technique occurred.

How do surgeons and other healthcare workers (HCWs) get infected in the first place? Until the early 1980 s, hepatitis B was a major occupational risk for HCWs. In 1989, the Center for Disease Control reported an annual rate of 4.89 cases per 1,000 exposed HCWs. ${ }^{6}$ In the United States, this translated to more than $12,000 \mathrm{HCW}$ s each year newly acquiring hepatitis $\mathrm{B}$, of whom $25 \%$ had clinical illness and $5 \%$ to $10 \%$ became long-term carriers. There is little to suggest that these rates were different anywhere in the Western world. Other studies have shown that infection rates and subsequent mortality rates were highest among those with the most blood contact (ie, surgeons, pathologists, emergency department staff, and technicians handling blood). Rates increased as a function of age and years of practice. ${ }^{7,8}$

Obviously, our first and foremost line of defense to prevent transmission of HBV from surgeon to patient is to prevent the infection in the surgeon in the first place. The hepatitis $B$ vaccine is both safe and efficacious. It provides immunity for $92 \%$ of individuals following a first series, with $5 \%$ to $8 \%$ remaining poor responders even after additional vaccine. ${ }^{9}$

The mere suggestion of mandatory immunization raises many cries. In 1998, when Health Canada proposed mandatory hepatitis $\mathrm{B}$ immunization for all $\mathrm{HCWs}$ performing exposure-prone procedures, the Canadian Medical Association and the Canadian Dental Association opposed this recommendation. ${ }^{10}$ Voluntary, frequently free vaccination has failed miserably in Canada; national surveys suggest that anywhere from $10 \%$ to $60 \%$ of surgeons and other HCWs who perform invasive procedures are not immunized. 
According to Zou et al. ${ }^{11}$ and unpublished data from Health Canada, 5 (11\%) of 45 patients with acute hepatitis B in 1999 reported a history of hospitalization; $2(6.7 \%)$ of them had no other risk factors. In 2000, $6(9.8 \%)$ of 61 patients with acute hepatitis $B$ reported a history of hospitalization and $3(6.3 \%)$ reported hospitalization as the exclusive risk factor. Incomplete results for January to October 2001 indicated that $4(9.3 \%)$ of 43 patients reported a history of hospitalization and $1(2.8 \%)$ had hospitalization as the exclusive risk factor. Although not conclusive due to the lack of reference data from the general population, these findings do suggest potential transmission of blood-borne pathogens in healthcare settings in Canada. How many of these "hospitalization" cases might be associated with invasive procedures performed by an $\mathrm{HCW}$ infected with hepatitis B?

Few, if any, countries have surveillance systems in place to provide the tracking and linking that is needed to readily and efficiently identify patients infected from their healthcare provider. Most nosocomial hepatitis B series in the literature have been identified by an astute laboratory technician or public health worker who noticed an increase in the number of new cases of hepatitis B in his or her reporting system. This then has led to extensive and expensive look-back studies, not infrequently identifying new cases.

In light of the cases reported in this issue of Infection Control and Hospital Epidemiology ${ }^{1}$ (in which both exposure-prone and non-exposure-prone procedures led to infection) and the frequency of nonresponsive and unimmunized $\mathrm{HCWs}$, more restrictive practice modification may need to be considered. These policies may include mandatory programs to promote immunization, ongoing surveillance projects to track nonresponders and those who refuse vaccination, and potential practice restrictions for $\mathrm{HBeAg}$-positive $\mathrm{HCW}$ s who perform invasive procedures. ${ }^{10}$ For example, Health Canada recommends that, after vaccination, HCWs need to know whether they have obtained adequate antibody protection. ${ }^{10}$ If, after repeated attempts at immunization, an HCW is nonresponsive, or if immunization is refused, screening and surveillance programs should be in place to regularly test this $\mathrm{HCW}$ for hepatitis $B$ infection. Those found to be positive for HBsAg should be tested for $\mathrm{HBeAg}$. Surgeons and others who perform invasive procedures who test positive for $\mathrm{HBeAg}$ may have their practice restricted. Recommendations from Health Canada $^{10}$ state that HBeAg-positive HCWs should cease practice until an expert panel (ie, composed of regulatory bodies and professional peers) evaluates their practice to identify modifications that may reduce the risk to patients. Finally, comprehensive surveillance programs that enable linkage from infected patients back to infected $\mathrm{HCWs}$ must be established.

Recently, Ross et al. ${ }^{12}$ reviewed seven cases of surgeons or anesthesiology staff infected with hepatitis $\mathrm{C}$ virus $(\mathrm{HCV})$ transmitting $\mathrm{HCV}$ to their patients during the course of medical care. In most cases, patients were infected through inadvertent exposure to the $\mathrm{HCWs}^{\prime}$ blood; only 2 incidents were caused by clear breaches of infection control practices. Ross et al. also detailed a 7year retrospective study that identified 1 case among 2,286 gynecology patients $(0.04 \% ; 95 \%$ confidence interval, $0.008 \%$ to $0.25 \%$ ). The transmission rates in these various look-back investigations varied from $0.04 \%$ to $2.7 \%$, suggesting that, although infrequent for some surgeons with hepatitis $\mathrm{C}$, transmission to patients has clearly been documented. We need many more in-depth examinations into the risk factors and transmission rates of $\mathrm{HCV}$ with different procedures. According to Zou et al. ${ }^{11}$ and unpublished data from Health Canada, 15 (18.8\%) of 80 patients with acute cases of $\mathrm{HCV}$ reported a history of hospitalization and $1(1.6 \%)$ reported it as the exclusive risk factor. For 2000 and January to October 2001, the rates were $21.6 \%$ (16 of 74 ) versus $4.4 \%$ ( 3 of 74 ) and $14.8 \%$ (8 of 54 ) versus $2.0 \%$ ( 1 of 54 ), respectively.

For human immunodeficiency virus (HIV), the incidence of transmission from infected HCW to patient is even lower. Six patients were potentially infected by a dentist in Florida during 1984 to 1989 . Infection control practices were questionable. ${ }^{13,14}$ One patient was infected from an orthopedic surgeon in France before 1992.15,16 Unlike the experience with hepatitis $\mathrm{B}$ and $\mathrm{C}$, numerous studies and surveillance projects have looked for a link between HIVinfected HCWs and infected patients and have failed to find one.

HCWs who perform invasive procedures of any kind have an ethical obligation to be immunized against hepatitis $B$ and to know their serologic status with reference to $\mathrm{HIV}, \mathrm{HBV}$, and $\mathrm{HCV}^{10}$ Infected HCWs pose an increasing order of risk to patients if they are HIV-, HCV-, HBsAg-, or $\mathrm{HBeAg-positive.} \mathrm{Standard} \mathrm{precautions} \mathrm{appear} \mathrm{to} \mathrm{be} \mathrm{effec-}$ tive in preventing transmission from an HIV-infected HCW. More study is required to identify the most effective, least restrictive modifications in practice and technique to reduce the risk of transmission from $\mathrm{HCV}$ - and HBsAg-positive HCWs. On the basis of the study by Spijkerman et al. ${ }^{1}$ and previous work done in this area, invasive surgery or other procedures performed by HBeAg-positive HCWs may pose an unacceptable risk to patients that may not be reducible by minor practice changes or enhanced infection control activities.

\section{REFERENCES}

1. Spijkerman IJB, van Doorn LJ, Janssen MHW, et al. Transmission of hepatitis $\mathrm{B}$ virus from a surgeon to his patients during high-risk and lowrisk surgical procedures during 4 years. Infect Control Hosp Epidemiol 2002;23:306-312.

2. Harpaz R, Von Seidlein L, Averhoff FM, Tormey M. Transmission of hepatitis $B$ virus to multiple patients from a surgeon without evidence of inadequate infection control. $N$ Engl J Med 1996;334:549-554.

3. Heptonstall J. Lessons from two linked clusters of acute hepatitis B in cardiothoracic surgery patients. CDR Review 1996;6:R119-R125.

4. Sundkvist T, Hamilton GR, Rimmer D, Evans BG, Teo CG. Fatal outcome of transmission of hepatitis $\mathrm{B}$ from an e antigen negative surgeon. Commun Dis Public Health 1998;1:48-50.

5. Johnston BL, Langille DB, LeBlanc JC, et al. Transmission of hepatitis B related to orthopedic surgery. Infect Control Hosp Epidemiol 1994;15: 352.

6. Occupational Safety and Health Administration. Occupational exposure to bloodborne pathogens. Federal Register 1989;54:23042-23139

7. Dienstag JL, Ryan DM. Occupational exposure to hepatitis B virus in 
hospital personnel: infection or immunization? Am I Epidemiol 1982;115:26-39.

8. Hadler SC, Doto IL, Maynard JE, et al. Occupational risk of hepatitis B infection in hospital workers. Infect Control 1985;6:24-31.

9. Health Canada. Canadian Immunization Guide, 5th ed. Ottawa, Ontario, Canada: Health Canada; 1998.

10. Health Canada. Proceedings of the consensus conference on infected health care workers: risk for transmission of bloodborne pathogens. Can Commun Dis Rep 1998;24S4:1-25.

11. Zou S, Zhang J, Tepper M, et al. Enhanced surveillance of acute hepatitis B and acute hepatitis C in four health regions in Canada, 1998 to 1999. Canadian Journal of Infectious Diseases 2001;12:357-363.
12. Ross RS, Viazov S, Thormählen $M$, et al. Risk of hepatitis $C$ virus transmission from an infected gynecologist to patients: results of a 7.year retrospective study. Arch Intern Med 2002;162:805-810.

13. Centers for Disease Control and Prevention. Recommended infection control practices for dentistry, 1993. MMWR 1993;42(RR-8):1-12.

14. Center for Disease Control. Update: transmission of HIV infection during invasive dental procedures-Florida. MMWR 1991;40:377-381.

15. Pugliese G, Favero MS. HIV transmission from surgeon to patient. Infect Control Hosp Epidemiol 1997;18:216-217.

16. Dorozynski A. French patient contracts AIDS from surgeon. Br Med J 1997;314:250. 